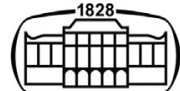

AKADÉMIAI KIADÓ

\title{
Perceived problems with adolescent online gaming: National differences and correlations with substance use
}

\section{Journal of Behavioral Addictions}

$9(2020) 3,629-641$

\section{DOI:}

10.1556/2006.2020.00061 (c) 2020 The Author(s)

\section{FULL-LENGTH REPORT}

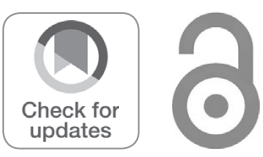

JULIAN STRIZEK ${ }^{1 *}$ ๑), JOSEFINE ATZENDORF ${ }^{2}$, LUDWIG KRAUS $^{3,4,5}$, KARIN MONSHOUWER ${ }^{6}$, ALEXANDRA PUHM ${ }^{1}$ and ALFRED UHL ${ }^{1,7}$

\author{
${ }^{1}$ Austrian Public Health Institute, Vienna, Austria \\ ${ }^{2}$ Munich Center for the Economics of Aging (MEA), Max-Planck-Institute for Social Law and Social \\ Policy, Munich, Germany \\ ${ }^{3}$ Institut für Therapieforschung, Munich, Germany \\ ${ }^{4}$ Department of Public Health Sciences, Stockholm University, Stockholm, Sweden \\ ${ }^{5}$ Institute of Psychology, ELTE Eötvös Loránd University, Budapest, Hungary \\ ${ }^{6}$ Trimbos Institute, Utrecht, The Netherlands \\ ${ }^{7}$ Sigmund-Freud Privat-Universität, Wien, Austria
}

Received: February 1, 2019 • Revised manuscript received: July 2, 2020 • Accepted: August 26, 2020

Published online: October 6, 2020

\begin{abstract}
Background: Not much is known about the correlation between gaming problems and substance use across different countries. This paper presents cross-national analyses of different gaming indicators and their relationship to substance use. Methods: Based on data from the 2015 ESPAD study, differences in the relationship between gaming and substance use across 35 countries were analysed using multi-level logistic regression, using substance use as an individual level predictor, economic wealth as a country-level predictor and a combined problem gaming indicator as the outcome. Results: Multi-level logistic regressions revealed significant correlations between individual substance use and gaming problems, which varied across countries and were moderated by economic wealth. Students who used alcohol, tobacco or cannabis and who lived in high-income countries had a smaller risk of scoring positively on a combined problem gaming indicator than students who used alcohol, tobacco or cannabis and who lived in less prosperous countries. Discussion: Different gaming indicators varied substantially across countries, with self-perceived gaming problems being more common in countries with a low prevalence of gaming. Significant cross-level effects demonstrate the need to take the societal context into account when the relationship between problem gaming and substance use is analysed. Prevention measures need to take the fact into account that patterns of substance use among problem gamers vary across countries.
\end{abstract}

\section{KEYWORDS}

online gaming, substance use, ESPAD, cross-level effect

\section{INTRODUCTION}

*Corresponding author.
E-mail: julian.strizek@goeg.at

Over the past few decades, video games have become a widespread social phenomenon and part of a booming gaming industry (Kuss, 2013). In line with a general growing scientific interest in behavioural addictions (Billieux, Schimmenti, Khazaal, Maurage, \& Heeren, 2015), more and more attention has been paid to problem gaming in recent years, with a special focus on certain types of games played on the Internet (e.g. MMORPGs, so-called "massively multiplayer online role-playing games"). The game mechanics of MMORPGs share all of the 
elements suspected of increasing gaming time excessively, including narrative features, game rewards and socialisation features (Nagygyörgy, 2013), and may lead to problem gaming.

As a result of the growing body of research on problem gaming, the diagnosis of "Internet Gaming Disorder" (IGD) was included in the annex of DSM-5 (emerging measures and models that need further research) for the first time (Petry \& O'Brien, 2013) and "Gaming Disorder" (GD) was added to the ICD-11 (WHO, 2018). Even though there is some evidence that IGD and GD share similarities with substance use disorders, more information on the aetiology and progression of IGD/GD is needed. Consequently, the debate as to whether it is justified to label these behaviours an "addiction" is controversial (Griffiths, Király, Pontes, \& Demetrovics, 2015). The inclusion of gaming disorder in the ICD-11 was supported by one group of researchers (Rumpf et al., 2018) and criticised by another (Van Rooij et al., 2018). Since there is no clear consensus on the definition of gaming disorder, some authors prefer the term "problem gaming", even though the criteria used are usually quite similar.

\section{Prevalence of gaming and problem gaming}

Data on the prevalence of gaming in European adolescents were obtained from two large international surveys. Results from the European School Survey Project on Alcohol and Other Drugs (ESPADs) in 2015 (ESPAD group, 2016a) indicate that $23 \%$ of ESPAD students (born in 1999) reported regular gaming (on 4 out of 7 days). Data from the Health Behaviour in School-aged Children Study in 2014 (HBSC) suggest that spending two or more hours on a weekday playing games on a computer, smartphone or games console is a common habit in 11 year olds $(37 \%$ on average), 13 year olds (45\% on average) and 15 year olds (42\% on average) (HBSC, 2016).

Griffiths et al. (2015) concluded that the prevalence of problem gaming varies considerably across different cultures and samples, ranging from less than $0.2 \%$ in Germany to $34 \%$ in Taiwan. The comparability of problem gaming prevalence estimates is impeded by the use of different scales being applied to assess problem gaming and a lack of consensus on the dimensions included in these scales (among them mood alteration, compulsive use, distraction, loneliness/depression, withdrawal, time management, tolerance and others) (Jia \& Jia, 2009). Ambiguity also arises from the fact that some scales assess gaming in general while others focus specifically on online gaming and still others include any Internet activities (Bischof, Bischof, Besser, \& Rumpf, 2016).

Population prevalence rates in South-East Asia usually exceed prevalence rates in Western countries by far. Results from Western countries, including Europe, report rates ranging from below $1 \%$ to up to $12 \%$. The large differences in the prevalence of self-reported problem gaming may be due to differences in gaming behaviour, access to games or to the societal effects of when gaming is classified as being problematic. It is very likely that all factors are relevant. In all countries the prevalence of problem gaming is much higher in boys than in girls (Van Rooij et al., 2014).

\section{Association between gaming and substance use}

In line with Problem-Behaviour Theory (Jessor, 1987), problem gaming might be a symptom of general problem behaviour, like problematic substance use and problem drinking. This hypothesis is supported by empirical findings suggesting that addictive behaviours often co-occur (Kotyuk et al., 2020), presumably because some individuals are more vulnerable to addictive behaviours than others due to differences in genetic or psychological predispositions like impulsivity (Van Rooij et al., 2014), lack of perseverance (Thomsen et al., 2018), variants of the dopamine receptors (Blum et al., 1996), ADHS (Romo et al., 2018), or other mental health problems (Marmet et al., 2019). A common aetiology for addictive behaviours is also suggested by the Component Model of Addiction (Griffith, 2005) that stresses common characteristics of different addictions. Škařupová, Blinka, and Tápal (2018) point out that at least some gamers use substances for game-related reasons (e.g. to enhance enjoyment), suggesting that co-occurring substance use is a pragmatic choice rather than an indicator of underlying problems. From all these perspectives we would expect a positive correlation between substance use and problem gaming. On the other hand, common sense tells us that all individuals only have a limited amount of spare time and therefore gaming activities in adolescents may lead to fewer activities outside their own home, where substance use by minors is more likely to happen. From this perspective we would expect a negative association between gaming and substance use.

Recent trend analyses using ESPAD data reveal a pronounced decrease in alcohol and tobacco use in 15- to 16year-old students over the last few years in Europe (ESPAD Group, 2016; Kraus et al., 2018), indicating a more general decrease in adolescents' substance use (Pennay et al., 2018). An increasing use of digital media may be one driving force behind this decline in youth drinking in Western societies, although this hypothesis has not yet been tested (Kraus et al., 2018). In the present paper, we used an explorative analysis to assess the association between gaming and substance use in general.

\section{Aim of the study}

Making use of the comparable methodology of the European School Survey Project on Alcohol and other Drugs (ESPADs), the aim of this paper was (1) to provide descriptive information on gaming activity and indicators of problem gaming across European countries, (2) to assess the relationship between problem gaming and substance use (alcohol, tobacco, cannabis) and (3) to test the effect of economic wealth on the relationship between problem gaming and substance use. 


\section{METHODS}

\section{Participants}

Data were taken from the 2015 ESPAD study, a cross-national survey performed in 35 European countries representing student populations who turned 16 in 2015. The countries collected data on students in accordance with consistent methodological guidelines using an anonymous self-administered questionnaire completed on a voluntary basis in classroom settings. Details on sampling and survey methodology as well as further information can be found elsewhere (ESPAD Group, 2016b).

All data were weighted if weights were provided in the national datasets. The data from Portugal and Belgium (Flanders) were not used for the analyses because perceived gaming problems were not included while the data from Ireland were not included in the multi-level analyses because class membership was missed out. Sample sizes by gender for all countries are provided in Table 6 in the Appendix.

\section{Measures}

Gaming indicators (outcome measures). Time loss is one of the most important negative effects of excessive gaming. A greater amount of time spent on gaming is considered a necessary condition for problem gaming, although this is not a sufficient indicator for problem gaming on its own (King, Haagsma, Delfabbro, Gradisar, \& Griffiths, 2013).

A three-item scale of perceived gaming problems (subsequently referred to as the perceived problems scale $=$ PPS) developed by Holstein et al. (2014) was used in all but two participating countries. In contrast to other scales assessing gaming addiction, the present scale does not use any of the DSM- 5 criteria but three items self-assessing the amount of time spent gaming ("I think I spend way too much time playing computer games"), the individual's mood when not gaming ("I get in a bad mood when I cannot spend time on computer games") and parents' perception of time spent gaming ("My parents tell me I spend way too much time on computer gaming"). According to the authors, a score of 2 or 3 (counting only the responses "strongly agree" and "agree") indicates gaming problems. The scale showed a high level of face validity and an acceptable level of internal consistency in a sample of Danish students (Holstein et al., 2014).

In the ESPAD survey, time spent on online gaming is assessed by (1) the number of days in the last week playing online games and (2) the number of hours on a typical day playing online games. These two items were combined to compute an average duration of time spent gaming per day (average gaming time $=\mathrm{AGT}$ ). In contrast to symptombased screening tools, there are no consistent thresholds to distinguish between periodic gaming, regular gaming and problem gaming when using the AGT. Holstein et al. (2014) provided evidence that an AGT of 1 hour or more per day already increased the risk of a positive score on the PPS. In a study by Marmet, Notari, and Gmel (2015), a screening instrument for problem gaming was only used with individuals with an AGT of 1 hour or more per day. In line with this research, the AGT was dichotomised using a threshold of 1 hour per day as a precondition for problem gaming.

A problem gaming index (PGI) as a proxy for measuring problem gaming was computed by combining the PPS and the AGT. The PGI was coded 1 if the AGT was 1 hour or more per day and if the PPS had a positive score; it was coded 0 if at least one of the two conditions was not fulfilled. In other words, 1 hour or more of gaming time per day was defined as the lower threshold for problem gaming.

Substance use (individual-level indicators). Substance use variables were re-coded into dichotomous variables, including alcohol use in the last 30 days (yes/no), smoking cigarettes in the last 30 days (yes/no) and lifetime cannabis use (yes/no). Different timeframes for prevalence estimates were used to avoid too low a prevalence rate.

Economic wealth (macro-level indicator). At a macro-level, the gross domestic product (GDP) per capita for 2015 was retrieved from an external data source (World Bank, 2018). GDP per capita is the gross domestic product divided by the mid-year population; it was aggregated for each country.

\section{Statistical analyses}

Gender differences were calculated as gender ratios, with a value above 1 indicating that boys were more likely to play games than girls (which is the case in all countries). Further descriptive information on a country level is provided by odds ratios (ORs), which were calculated to assess the risk relation between problem gaming and substance use. For the bivariate analyses, the PGI was used because the combination of self-assessment (PPS) and minimum gaming time (AGT) was considered less prone to being confounded by either cultural or economic factors than the PPS or the AGT alone. Due to the fact that only a very small proportion of girls scored positively on the PGI, all bivariate analyses were run for boys only. These descriptive analyses were not controlled for potential cluster effects and thus no significance levels or confidence intervals were calculated.

Regression analyses are based on the assumption that residuals are independent from each other (Field, 2013), which might not be true for nested data. In our data, students (Level 1) were nested within school classes (Level 2) which were nested within countries (Level 3). To test the effects between substance use, the PGI and economic wealth for significance, a three-level logistic regression analysis was performed to account for the hierarchical structure of the data, resulting in corrected standard errors (Raudenbush \& Bryk, 2002; Hox, 2010). The Median Odds Ratio (MOR) was used to measure the effect of heterogeneity between school classes and countries. The MOR can be conceptualised as the median increased risk if one individual moved from a cluster with a lower risk to a cluster with a higher risk (Merlo et al., 
2006). In our study, a MOR equal to one indicates no differences between classes and countries in the risk of scoring positively on the PGI for students using alcohol, tobacco or cannabis. By contrast, a MOR greater than one indicates cluster effects and that cluster membership is relevant for understanding variations in the probability of a positive score on the PGI. The Akaike Information Criterion (AIC) was used to assess the fit of the model. A smaller value of the AIC indicates that a certain model has a reduced mean squared error and is therefore more precise in its predictions (Vrieze, 2012).

In accordance with the literature on multi-level logistic regression (Sommet \& Morselli, 2017), we used a step-wise approach: In the first step, no predictors were included in the model in order to estimate whether the PGI varied between school classes and countries (intercept-only model). Different levels of the PGI across school classes and countries were indicated by significant variance components. Next, predictors at the individual level (substance consumption) and at the macro-level (GDP) were included as fixed effects with random intercepts in order to estimate the direct associations between the predictors and the outcome measure without taking variations between school classes and countries into account (fixed predictors with randomintercept model). In a third step, random slopes were included in the model in order to assess whether the associations between individual-level predictors and outcome measures varied between school classes and countries (random-intercept and random-slope model). Different associations between the PGI and the predictors across school classes and countries were indicated by significant variance components. Finally, cross-level interactions between individual-level and macro-level variables were included in order to assess whether the different associations between the PGI and substance consumption across the countries could be explained by economic wealth (random-intercept and random-slope model with cross-level interaction). Significant regression coefficients indicated a significant effect for the cross-level interactions. Furthermore, a decreasing value of the AIC indicated a better fit of the model compared to the intercept-only model.

Similar to the bivariate analyses, only male students were included in the multilevel logistic regression. GDP was recoded into three categories based on the terciles of the distribution of GDP on country level. The least wealthy group of countries (GDP per capita $<\$ 13,000$ ) was coded 1 and consists of the Republic of Moldova, Ukraine, Georgia, Albania, FYR of Macedonia, Montenegro, Bulgaria, Romania, Croatia, Hungary and Poland. The middle group of countries (\$13,000 $<\$ 40,000)$ was coded 2 and consists of Latvia, Lithuania, the Slovak Republic, Estonia, the Czech Republic, Greece, Slovenia, Cyprus, Malta, Italy and France. The wealthiest group of countries (GPD per capita $>\$ 40,000$ ) was coded 3 and consists of Germany (Bavaria), Finland, Austria, the Netherlands, the Faroe Islands, Sweden, Iceland, Denmark, Norway and Liechtenstein (countries in all three groups are arranged in order of GDP per capita).

Separate models were run for alcohol, tobacco and cannabis use since a model with all three level-1 predictors did not converge when random slopes were assumed. To compensate for multiple testing, the alpha level of 0.05 was divided by three and set to 0.017 after the analyses (Bonferroni correction). Descriptive analyses were performed using SPSS 23 (IBM Corp., Armonk, NY) and multilevel logistic regression models were performed using Stata 14 (Stata Corp LP, College Station, TX). Cases with missing data were deleted list wise.

\section{Ethics}

According to the ESPAD methodology, the students were informed that answering the questionnaire was voluntary and that responses to survey questions were confidential and anonymous. In addition, all surveys complied with the relevant national laws, regulations and guidelines concerning research ethics (ESPAD Group, 2016b).

\section{RESULTS}

\section{Prevalence of problem gaming indicators across European countries}

Overall, the prevalence of students scoring positively on the PPS and the number of students with an AGT of at least $1 \mathrm{~h}$ per day were rather similar at 20.3 and $21.0 \%$, respectively (Table 1 ). However, on a country level the two indicators varied substantially. The proportion of students with a positive score on the PPS ranged from $13 \%$ in Germany (Bavaria) and Liechtenstein to $31.8 \%$ in Latvia ( $\mathrm{SD}=5.5$ across countries) while the proportion of students with an AGT exceeding 1 hour per day ranged from almost $13 \%$ in Albania, Macedonia and Georgia to $38.4 \%$ in Denmark ( $\mathrm{SD}=6.2$ across countries). Countries tended to have a high score either on the PPS (notably South Eastern European countries) or on the AGT (notably Northern European countries) while only very few countries tended to score high on both scales (notably Baltic countries) (cf. Fig. 1).

Based on the PGI, differences in the prevalence of problem gaming were smaller $(\mathrm{SD}=2.2)$, ranging from $4.8 \%$ in Ukraine to $13.6 \%$ in Latvia. The total prevalence of the PGI was $8.5 \%$, with male students being 9 times more likely to score positively on the PGI than female students. Gender differences can also be observed for the two single indicators, with a more pronounced gender ratio in favour of male students for gaming time (male students were 6.7 times more likely to play more than $1 \mathrm{~h}$ per day on average) than for perceived gaming problems (male students were 3.1 times more likely to self-report gamerelated problems).

\section{Bivariate analyses between the PGI and substance use in male students}

The associations between problem gaming and substance use indicators, i.e. whether male students who fulfil the criteria for the PGI have a higher likelihood of using a 
Table 1. Scores of the gaming indicators PPS, AGT and PGI by country

\begin{tabular}{|c|c|c|c|c|c|c|}
\hline & \multicolumn{2}{|c|}{ PPS (2-3 pts) } & \multicolumn{2}{|c|}{ AGT $(1 \mathrm{~h}+)$} & \multicolumn{2}{|c|}{ PGI } \\
\hline & $\begin{array}{c}\text { Total prevalence } \\
\text { (\%) }\end{array}$ & $\begin{array}{c}\text { Gender ratio } \\
(\mathrm{m}: \mathrm{f})\end{array}$ & $\begin{array}{c}\text { Total prevalence } \\
\text { (\%) }\end{array}$ & $\begin{array}{c}\text { Gender ratio } \\
\text { (m:f) }\end{array}$ & $\begin{array}{c}\text { Total prevalence } \\
\text { (\%) }\end{array}$ & $\begin{array}{c}\text { Gender ratio } \\
(\mathrm{m}: \mathrm{f})\end{array}$ \\
\hline Albania & 27.6 & 2.1 & 12.7 & 3.1 & 7.5 & 3.7 \\
\hline Austria & 14.8 & 5.8 & 22.5 & 7.9 & 9.1 & 14.9 \\
\hline Bulgaria & 29.8 & 2.2 & 22.9 & 4.8 & 10.6 & 5.2 \\
\hline Croatia & 21.8 & 3.1 & 20.5 & 6.9 & 9.9 & 8.3 \\
\hline Cyprus & 23.8 & 2.2 & 20.8 & 5.0 & 9.3 & 5.5 \\
\hline Czech Republic & 16.8 & 5.8 & 25.3 & 7.3 & 11.0 & 10.6 \\
\hline Denmark & 14.2 & 5.6 & 38.4 & 2.7 & 10.1 & 7.7 \\
\hline Estonia & 17.4 & 4.9 & 32.4 & 8.7 & 12.9 & 12.3 \\
\hline Faroe Islands & 26.4 & 4.6 & 26.5 & 16.1 & 14.6 & 73.5 \\
\hline Finland & 14.1 & 5.3 & 26.1 & 11.4 & 9.1 & 14.2 \\
\hline France & 17.8 & 4.1 & 22.4 & 8.3 & 9.3 & 10.9 \\
\hline FYR of Macedonia & 29.3 & 1.8 & 12.8 & 5.0 & 6.9 & 5.2 \\
\hline Germany (Bavaria) & 12.9 & 7.0 & 24.8 & 7.0 & 9.4 & 9.3 \\
\hline Georgia & 23.9 & 3.6 & 12.5 & 14.7 & 7.7 & 25.7 \\
\hline Greece & 17.1 & 4.1 & 15.7 & 12.9 & 7.7 & 14.7 \\
\hline Hungary & 17.6 & 4.6 & 20.3 & 5.5 & 8.8 & 7.9 \\
\hline Iceland & 12.9 & 4.8 & 23.0 & 14.4 & 6.8 & 17.8 \\
\hline Ireland & 16.2 & 5.7 & 19.0 & 8.7 & 8.4 & 16.1 \\
\hline Italy & 22.9 & 2.4 & 16.1 & 3.2 & 7.1 & 4.7 \\
\hline Latvia & 31.8 & 1.7 & 28.7 & 6.3 & 13.6 & 11.1 \\
\hline Liechtenstein & 12.7 & 6.9 & 22.6 & 27.5 & 6.3 & 23.1 \\
\hline Lithuania & 25.1 & 2.7 & 29.3 & 4.4 & 11.4 & 7.4 \\
\hline Malta & 23.7 & 3.4 & 22.9 & 5.4 & 11.8 & 8.3 \\
\hline $\begin{array}{l}\text { Moldova, } \\
\text { Republic of }\end{array}$ & 28.9 & 1.8 & 14.0 & 9.2 & 6.3 & 9.4 \\
\hline Montenegro & 26.2 & 2.7 & 14.6 & 6.6 & 8.1 & 6.9 \\
\hline Netherlands & 16.0 & 4.0 & 30.0 & 7.2 & 10.0 & 11.2 \\
\hline Norway & 14.3 & 4.8 & 28.2 & 10.6 & 8.4 & 16.1 \\
\hline Poland & 15.4 & 4.1 & 22.4 & 7.5 & 8.5 & 9.3 \\
\hline Romania & 26.7 & 2.1 & 19.4 & 6.1 & 8.2 & 8.7 \\
\hline Slovak Republic & 21.2 & 3.8 & 20.9 & 4.2 & 8.9 & 7.9 \\
\hline Slovenia & 18.8 & 4.7 & 16.6 & 9.2 & 7.8 & 9.4 \\
\hline Sweden & 20.3 & 3.3 & 32.4 & 11.1 & 12.7 & 13.2 \\
\hline Ukraine & 16.9 & 2.1 & 15.9 & 6.3 & 4.8 & 3.6 \\
\hline Total & 20.3 & 3.1 & 21.0 & 6.7 & 8.5 & 8.9 \\
\hline
\end{tabular}

Notes: PPS = perceived problems scale; AGT = average gaming time; PGI = problem gaming indicator.
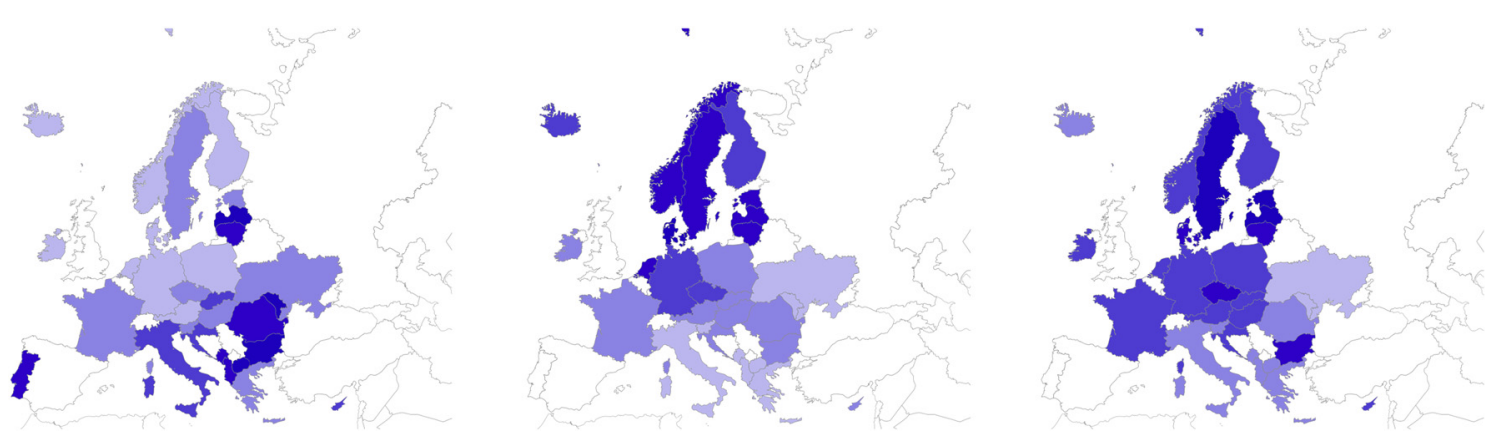

Fig. 1. Heat maps based on the prevalence of the PPS (left), the AGT (middle) and the PGI. PPS = perceived problems scale. PPS = perceived problems scale; AGT = average gaming time; PGO = problem gaming indicator; dark blue indicates high values, light blue indicates low values, Source: 2015 ESPAD Survey 
Table 2. Bivariate associations between the PGI and substance use indicators (male students only)

\begin{tabular}{|c|c|c|c|}
\hline & $\begin{array}{c}\text { ORs of } \\
\text { scoring } \\
\text { positively on } \\
\text { the PGI and } \\
\text { alcohol use in } \\
\text { the last } 30 \\
\text { days }\end{array}$ & $\begin{array}{c}\text { ORs of } \\
\text { scoring } \\
\text { positively on } \\
\text { the PGI and } \\
\text { smoking } \\
\text { cigarettes in } \\
\text { the last } 30 \\
\text { days }\end{array}$ & $\begin{array}{l}\text { ORs of } \\
\text { scoring } \\
\text { positively on } \\
\text { the PGI and } \\
\text { lifetime } \\
\text { cannabis use }\end{array}$ \\
\hline Albania & 1.9 & 1.4 & 1.5 \\
\hline Austria & 0.6 & 0.7 & 0.7 \\
\hline Bulgaria & 0.9 & 0.9 & 1.3 \\
\hline Croatia & 1.1 & 0.9 & 0.8 \\
\hline Cyprus & 1.3 & 0.7 & 0.9 \\
\hline $\begin{array}{l}\text { Czech } \\
\text { Republic }\end{array}$ & 0.7 & 0.8 & 1.0 \\
\hline Denmark & 0.8 & 0.4 & 0.4 \\
\hline Estonia & 0.8 & 0.8 & 0.8 \\
\hline Faroe Islands & 0.9 & 1.4 & 1.2 \\
\hline Finland & 0.7 & 0.5 & 0.7 \\
\hline France & 0.8 & 0.6 & 0.7 \\
\hline $\begin{array}{l}\text { FYR } \\
\quad \text { Macedonia }\end{array}$ & 2.1 & 1.1 & 1.4 \\
\hline $\begin{array}{l}\text { Germany } \\
\text { (Bavaria) }\end{array}$ & 0.7 & 0.6 & 0.6 \\
\hline Georgia & 2.8 & 0.8 & 1.0 \\
\hline Greece & 0.8 & 0.9 & 0.9 \\
\hline Hungary & 0.9 & 0.6 & 0.7 \\
\hline Iceland & 0.7 & 0.4 & 0.7 \\
\hline Ireland & 0.7 & 0.7 & 1.0 \\
\hline Italy & 1.2 & 1.1 & 0.9 \\
\hline Latvia & 0.6 & 0.3 & 0.5 \\
\hline Liechtenstein & 0.2 & 0.7 & 0.5 \\
\hline Lithuania & 1.2 & 0.9 & 0.8 \\
\hline Malta & 0.9 & 0.9 & 0.8 \\
\hline $\begin{array}{l}\text { Moldova, } \\
\text { Republic of }\end{array}$ & 1.0 & 1.1 & 0.8 \\
\hline Montenegro & 1.2 & 1.0 & 1.0 \\
\hline Netherlands & 0.9 & 0.7 & 0.8 \\
\hline Norway & 0.8 & 1.0 & 1.0 \\
\hline Poland & 1.0 & 0.7 & 0.9 \\
\hline Romania & 1.0 & 0.9 & 1.1 \\
\hline $\begin{array}{l}\text { Slovak } \\
\quad \text { Republic }\end{array}$ & 1.3 & 0.4 & 1.1 \\
\hline Slovenia & 1.0 & 0.9 & 1.2 \\
\hline Sweden & 0.7 & 0.6 & 0.7 \\
\hline Ukraine & 1.0 & 0.8 & 1.2 \\
\hline Total & 0.9 & 0.8 & 0.9 \\
\hline
\end{tabular}

Source: 2015 ESPAD survey.

particular substance in the selected timeframe, are displayed in Table 2. The differences in ORs across countries were higher for alcohol use than for smoking cigarettes or cannabis use. The ORs for the PGI and alcohol use within the last 30 days ranged from 0.2 in Liechtenstein and 0.6 in Austria to 2.8 in Georgia. The ORs for the PGI and cigarette use in the last 30 days ranged from 0.4 in Iceland and the Slovak Republic to 1.4 in Albania and the Faroe Islands. Finally, the ORs for the PGI and cannabis use ranged from 0.5 in Liechtenstein and Lithuania to 1.5 in Albania.
The results in Table 2 show inconsistent patterns for the bivariate associations between gaming and substance use indicators. Across countries, problem gaming is not consistently associated with a higher or a lower level of substance use. Positive correlations can be found in some countries while they are negative in others.

\section{Testing for significant effects of individual-level and country-level predictors using multi-level logistic regression}

Intercept-only model. The variance component for the intercept-only model of the PGI was statistically significant (not shown in Table 3), indicating that prevalence rates of the PGI differed between school classes and countries (MOR $=1.7, \mathrm{AIC}=34795.78$ ).

Fixed predictors with random intercepts. At the individual level, alcohol consumption was not significantly associated with the PGI (Table 3). The consumption of cannabis $(\mathrm{OR}=$ $0.88 ; 95 \%-\mathrm{KI}=[0.81 ; 0.97])$ and smoking $(\mathrm{OR}=0.77 ; 95 \%$ $\mathrm{KI}=[0.70 ; 0.85])$ were significantly associated with a lower chance of scoring positively on the PGI (Tables 4 and 5). At the macro-level, the direct effect of GDP was not significantly associated with the PGI $\left(\mathrm{AIC}_{\text {Alcohol }}=34323.49\right.$; $\left.\mathrm{AIC}_{\text {Smoking }}=34649.52, \mathrm{AIC}_{\text {Cannabis }}=34595.12\right)$.

Random-intercept and random-slope model. The variance components showed that the associations between the PGI and smoking and the consumption of cannabis varied among school classes and countries (Tables 4 and 5). Smaller values of the AIC indicate that precision increased compared to the models with fixed predictors $\left(\mathrm{AIC}_{\mathrm{Alcohol}}=34286.35\right.$; $\left.\mathrm{AIC}_{\text {Smoking }}=34638.68, \mathrm{AIC}_{\text {Cannabis }}=34594.56\right)$. The MORs were greater than one for all substances, indicating strong country-level differences regarding the associations between substance consumption and gaming problems $\left(\mathrm{MOR}_{\text {Alcohol }}\right.$ $\left.=1.29, \mathrm{MOR}_{\text {Smoking }}=1.61, \mathrm{MOR}_{\text {Cannabis }}=1.48\right)$.

Random-intercept and random-slope model with crosslevel interaction. There was a statistically significant crossinteraction between GDP and substance use on the PGI. With regard to alcohol, as alcohol consumption changes from abstinence (0) to consumption (1) in combination with living in the wealthiest group of ESPAD countries, the change in the odds of scoring positively on the PGI is 0.57 compared to the least wealthy group of countries (reference). In other words, for students living in the wealthiest group of ESPAD countries, alcohol consumption was less likely to contribute to the PGI. The odds ratios for the cross-interaction of the second group of countries did not show any statistically significant effect after correcting the alpha value (Bonferroni).

Similar to the model with alcohol as an individual predictor, significant cross-interaction also existed for the wealthiest group of countries for cannabis (OR $=0.67 ; 95 \%$ $\mathrm{CI}=[0.54 ; 0.84])$ and for tobacco use $(\mathrm{OR}=0.69 ; 95 \%-\mathrm{C}=$ I $[0.56 ; 0.84]$. Again, for the second group of countries the cross-interaction effects were not statistically significant. 
Table 3. Results of multilevel analyses predicting the associations between the PGI and alcohol consumption (male students only)

\begin{tabular}{|c|c|c|c|c|c|c|}
\hline \multirow[b]{2}{*}{ Fixed effects } & \multicolumn{2}{|c|}{$\begin{array}{c}\text { Fixed predictors with } \\
\text { random intercepts ICC } 0.27 \text {, } \\
\text { AIC } 34323.49\end{array}$} & \multicolumn{2}{|c|}{$\begin{array}{l}\text { Random-intercept and } \\
\text { random-slope model ICC } \\
0.27 \text {, AIC } 34286.35\end{array}$} & \multicolumn{2}{|c|}{$\begin{array}{l}\text { Random-intercept and } \\
\text { random-slope model with } \\
\text { cross-level interaction ICC } \\
0.27 \text {, AIC } 34273.07\end{array}$} \\
\hline & OR & $95 \%-C I$ & OR & 95\%-CI & OR & $95 \%-\mathrm{CI}$ \\
\hline Intercept & $0.15^{\star}$ & {$[0.12 ; 0.18]$} & $0.14^{*}$ & {$[0.11 ; 0.17]$} & $0.13^{*}$ & {$[0.11 ; 0.16]$} \\
\hline Aggr. GDP & & & & & - & - \\
\hline 1\#GDP & Ref. & & Ref. & & Ref. & \\
\hline 2\#GDP & 0.97 & {$[0.43 ; 2.17]$} & 1.08 & {$[0.47 ; 2.45]$} & 1.11 & {$[0.49 ; 2.54]$} \\
\hline 3\#GDP & 0.86 & {$[0.34 ; 2.18]$} & 1.03 & {$[0.39 ; 2.70]$} & 1.12 & {$[0.44 ; 2.86]$} \\
\hline Alcohol consumption & 0.96 & {$[0.86 ; 1.07]$} & 0.93 & {$[0.82 ; 1.06]$} & 1.19 & {$[0.96 ; 1.49]$} \\
\hline Interaction with $1 \#$ GDP & & & & & Ref. & \\
\hline Interaction with $2 \#$ GDP & & & & & 0.77 & {$[0.60 ; 0.99]$} \\
\hline Interaction with $3 \# \mathrm{GDP}$ & & & & & $0.57^{*}$ & {$[0.44 ; 0.73]$} \\
\hline Random effects & Var. (SE) & $95 \%-\mathrm{CI}$ & Var. (SE) & $95 \%-\mathrm{CI}$ & Var. (SE) & $95 \%-\mathrm{CI}$ \\
\hline Intercept & $0.21(0.04)$ & {$[0.14 ; 0.31]$} & $0.19(0.04)$ & {$[0.13 ; 0.27]$} & $0.19(0.03)$ & {$[0.13 ; 0.27]$} \\
\hline Alcohol consumption & - & & $0.07(0.05)$ & {$[0.02 ; 0.30]$} & $0.07(0.50)$ & {$[0.02 ; 0.31]$} \\
\hline
\end{tabular}

Note: Ref. = Reference; Aggr. = aggregated; OR = odds ratio; 95\%-CI = 95\% confidence interval; SEs = robust standard errors; Var. $=$ variance component.

${ }^{*} P<0.017$.

Models for all substances with cross-level interaction revealed smaller values for the $\mathrm{AIC}\left(\mathrm{AIC}_{\mathrm{Alcohol}}=34273.07\right.$; $\mathrm{AIC}_{\text {Smoking }}=34634.55 ; \mathrm{AIC}_{\text {Cannabis }}=34585.4$ ), indicating increased precision compared to the model without crosslevel interaction.

\section{DISCUSSION}

Our analyses revealed that gaming time and perceived problems were very unevenly distributed across ESPAD countries. There is a consensus that a certain amount of gaming time is a precondition for gaming problems but an insufficient stand-alone indicator for problem gaming on an individual level. Using a minimum gaming time of 1 hour per day as a threshold for a perceived problem scale (PPS), combining the AGT with the PPS has a considerable effect on prevalence estimates for gaming problems compared to using the PPS without any minimum threshold (8.5 vs. $20.3 \%$ in the ESPAD sample).

In line with the vast majority of research in this area, male students scored much higher on any gaming indicator

Table 4. Results of multilevel analyses predicting the associations between the PGI and smoking (male students only)

\begin{tabular}{|c|c|c|c|c|c|c|}
\hline \multirow[b]{2}{*}{ Fixed effects } & \multicolumn{2}{|c|}{$\begin{array}{c}\text { Fixed predictors with } \\
\text { random intercepts ICC } 0.27 \text {, } \\
\text { AIC } 34649.52\end{array}$} & \multicolumn{2}{|c|}{$\begin{array}{l}\text { Random-intercept and } \\
\text { random-slope model ICC } \\
0.27 \text {, AIC } 34638.68\end{array}$} & \multicolumn{2}{|c|}{$\begin{array}{l}\text { Random-intercept and } \\
\text { random-slope model with } \\
\text { cross-level interaction ICC } \\
0.27 \text { AIC } 34634.55\end{array}$} \\
\hline & OR & $95 \%-\mathrm{CI}$ & OR & $95 \%-\mathrm{CI}$ & OR & $95 \%-\mathrm{CI}$ \\
\hline Intercept & $0.15^{*}$ & {$[0.13 ; 0.18]$} & $0.15^{*}$ & {$[0.13 ; 0.18]$} & $0.15^{*}$ & {$[0.13 ; 0.18]$} \\
\hline Aggr. GDP & & & & & - & - \\
\hline 1\#GDP & Ref. & & Ref. & & Ref. & \\
\hline 2\#GDP & 0.97 & {$[0.43 ; 2.18]$} & 0.98 & {$[0.43 ; 2.23]$} & 1.00 & {$[0.44 ; 2.28]$} \\
\hline 3\#GDP & 0.86 & {$[0.34 ; 2.18]$} & 0.88 & {$[0.34 ; 2.25]$} & 0.91 & {$[0.35 ; 2.34]$} \\
\hline Smoking & $0.77^{*}$ & {$[0.70 ; 0.85]$} & $0.70^{*}$ & {$[0.60 ; 0.81]$} & $0.81^{\star}$ & {$[0.71 ; 0.93]$} \\
\hline Interaction with $1 \#$ GDP & & & & & Ref. & \\
\hline Interaction with $2 \# \mathrm{GDP}$ & & & & & 0.85 & {$[0.67 ; 1.07]$} \\
\hline Interaction with $3 \# \mathrm{GDP}$ & & & & & $0.69^{*}$ & {$[0.56 ; 0.84]$} \\
\hline Random effects & Var. (SE) & $95 \%-\mathrm{CI}$ & Var. (SE) & $95 \%-\mathrm{CI}$ & Var. (SE) & $95 \%-\mathrm{CI}$ \\
\hline Intercept & $0.20(0.04)$ & {$[0.13 ; 0.30]$} & $0.19(0.04)$ & {$[0.13 ; 0.29]$} & $0.19(0.04)$ & {$[0.13 ; 0.29]$} \\
\hline Smoking & - & & $0.25(0.14)$ & {$[0.08 ; 0.75]$} & $0.25(0.14)$ & {$[0.08 ; 0.75]$} \\
\hline
\end{tabular}

Notes: Ref. = Reference; Aggr. = aggregated; OR = odds ratio; 95\%-CI = 95\% confidence interval; SEs = robust standard errors; Var. $=$ variance component.

${ }^{*} P<0.017$. 
Table 5. Results of multilevel analyses predicting the associations between the PGI and cannabis use (male students only)

\begin{tabular}{|c|c|c|c|c|c|c|}
\hline \multirow[b]{2}{*}{ Fixed effects } & \multicolumn{2}{|c|}{$\begin{array}{c}\text { Fixed predictors with } \\
\text { random intercepts ICC } 0.27 \text {, } \\
\text { AIC } 34595.12\end{array}$} & \multicolumn{2}{|c|}{$\begin{array}{l}\text { Random-intercept and } \\
\text { random-slope model ICC } \\
0.27 \text {, AIC } 34594.56\end{array}$} & \multicolumn{2}{|c|}{$\begin{array}{l}\text { Random-intercept and } \\
\text { random-slope model with } \\
\text { cross-level interaction ICC } \\
0.27 \text { AIC } 34585.4\end{array}$} \\
\hline & OR & $95 \%-\mathrm{CI}$ & OR & $95 \%-C I$ & OR & $95 \%-\mathrm{CI}$ \\
\hline Intercept & $0.15^{*}$ & {$[0.13 ; 0.18]$} & $0.15^{*}$ & {$[0.13 ; 0.17]$} & $0.15^{*}$ & {$[0.12 ; 0.17]$} \\
\hline Aggr. GDP & & & & & - & - \\
\hline 1\#GDP & Ref. & & Ref. & & Ref. & \\
\hline 2\#GDP & 0.98 & {$[0.44 ; 2.21]$} & 0.99 & {$[0.44 ; 2.22]$} & 1.00 & {$[0.44 ; 2.26]$} \\
\hline 3\#GDP & 0.88 & {$[0.34 ; 2.23]$} & 0.89 & {$[0.35 ; 2.27]$} & 0.93 & {$[0.36 ; 2.38]$} \\
\hline Cannabis & $0.88^{*}$ & {$[0.80 ; 0.96]$} & $0.82^{*}$ & {$[0.72 ; 0.95]$} & 0.96 & {$[0.82 ; 1.12]$} \\
\hline Interaction with $1 \# \mathrm{GDP}$ & & & & & Ref. & \\
\hline Interaction with $2 \#$ GDP & & & & & 0.88 & {$[0.73 ; 1.05]$} \\
\hline Interaction with $3 \#$ GDP & & & & & $0.67^{*}$ & {$[0.54 ; 0.84]$} \\
\hline Random effects & Var. (SE) & $95 \%-\mathrm{CI}$ & Var. (SE) & $95 \%-\mathrm{CI}$ & Var. (SE) & $95 \%-\mathrm{CI}$ \\
\hline Intercept & $0.20(0.04)$ & {$[0.13 ; 0.30]$} & $0.19(0.04)$ & {$[0.13 ; 0.29]$} & $0.19(0.04)$ & {$[0.13 ; 0.29]$} \\
\hline Cannabis & - & & $0.17(0.18)$ & {$[0.02 ; 1.32]$} & $0.16(0.17)$ & {$[0.02 ; 1.32]$} \\
\hline
\end{tabular}

Notes: Ref. $=$ Reference; Aggr. = aggregated; $\mathrm{OR}=$ odds ratio; $95 \%-\mathrm{CI}=95 \%$ confidence interval; SEs $=$ robust standard errors; Var. $=$ variance component.

${ }^{*} P<0.017$.

in all ESPAD countries. However, the gender ratio for the PPS was much smaller than for the AGT, indicating that girls were more likely than boys to perceive their gaming behaviour as being problematic. Without in-depth analyses using a "gold standard" of gaming problem behaviour, it is not possible to conclude whether girls actually need less gaming time to experience subjective problems or whether this self-evaluation problem scale would need different cutoff scores for girls and boys.

The negative correlation between gaming time and perceived gaming problems on a country level (despite a positive correlation on an individual level) adds contextual information to the findings, i.e. the more widespread gaming is in a given country, the lower the number of students who see themselves being at risk of gaming problems (and vice versa). This result supports the idea that perceived problems might be more strongly related to the social status of gaming, e.g. whether gaming is considered normal or not according to cultural norms and only weakly related to actual gaming behaviour. Similar results were found for subjective intoxication and levels of per capita consumption in US trend data (Kerr, Greenfield, \& Midanik, 2006). However, with regard to gaming it might be the case that other symptom scales are more closely related to the actual problem level. It is, of course, also possible that different assessments of perceived problems indicate "true" differences, since the population of adolescent gamers in one country may be more vulnerable to gaming problems than in other countries.

ORs between problem gaming and substance use showed an inconsistent pattern across European countries. In highincome countries the association tended to be negative. This negative association has some face validity, considering the fact that in many cases, playing computer games will take place at home and substance use will often take place away from parental supervision. This association also supports the hypothesis that the use of digital media may be one contributing factor to the decline of substance use in adolescents across some Western European countries (Kraus et al. 2020; Room et al. 2019). In contrast, in countries with a low GDP per capita, we found a positive association between problem gaming and substance use. The fact that we used a measure for substance use instead of a measure for substance use disorders may also explain why our results differ from other research suggesting a consistent positive association between behavioural addiction and substance use disorders.

Multi-level logistic regression revealed statistically significant cross-level effects between substance use and GDP on the PGI. The odds of scoring positively on the PGI differed statistically significantly between individuals who used alcohol, cannabis or tobacco and lived in the wealthiest group of countries compared to students who used alcohol, cannabis or tobacco and lived in the least wealthy group of countries. Accordingly, use of these substances in the wealthiest countries was less likely to be associated with problem gaming than in the least prosperous countries. By contrast, there were no statistically significant cross-level effects for the second group of countries and no direct effects of GDP on the PGI in any of the three models. One possible interpretation is that the effect of competing leisure activities requires a rather higher level of prosperity because only then do a variety of leisure activities become widely available for all adolescents and not only to selective subpopulations such as students in urban areas or students living in less traditional families, who might be more likely to be involved in both online games and substance use despite limited spare time. 


\section{LIMITATIONS}

Several limitations should be considered when interpreting the results presented in this study. Firstly, it is important to stress that neither gaming time, perceived problems nor the combination of both indicators are a valid measure of gaming disorder with clinical relevance. Neither does any of the substance use indicators included necessarily indicate problem behaviour. The measure used in the ESPAD study is a rather short self-assessment scale; more sophisticated scales might produce other results.

Secondly, the cross-sectional design of youth surveys like the ESPAD study does not allow us to distinguish between low prevalence and postponed substance use. For countries with ORs on the PGI and substance use below 1, this may be an indication of postponed substance use rather than a longterm decline in use.

Thirdly, cross-sectional data on behavioural indicators do not provide information on how problem behaviour may develop over time. Problem behaviour in general peaks in adolescence and in many cases ceases without intervention (Moffitt, 1993). Longitudinal designs may help to provide a more solid foundation for the temporal evolution of potential problem behaviours like gaming and substance use in adolescents.

Fourthly, we did not succeed in computing a model including all three level-1 predictors with random slopes in one single model in either SPSS or STATA. Problems reaching convergence in models with multiple random slopes are described elsewhere (Sommet \& Morselli, 2017); still a model with three level-1 predictors and random slopes may have produced different results. According to the fixedeffect model with three level-1 predictors, cannabis did not have a statistically significant effect on the PGI. The same result was obtained by the final cannabis model (randomintercept and random-slope model with cross-level interaction).

With respect to the AGT, other thresholds may be used for this indicator since there is no clear threshold to distinguish between periodic gaming, regular gaming and problem gaming based on average gaming time. Using a threshold of 2 hours per day instead of 1 hour per day reduces prevalence estimates for the PGI (from 8.5 to $6.7 \%$ ), leads to even bigger gender disparities and the ORs for the PGI and substance use changed slightly (see Tables 7 and 8 in the Appendix).

\section{CONCLUSIONS AND FURTHER DIRECTIONS}

Cross-national surveys using harmonised instruments like the ESPAD are an essential source of information to compare gaming indicators across a large number of countries. However, the inconsistency of the association between gaming and substance use stresses the importance of considering context variables on a country level. Further research is needed to understand the effect of context variables in more detail and should also take differences into account in the characteristics of young people playing online games across countries.

Funding sources: JS, AP and AU received funding by an internal publication grant provided by Gesundheit Österreich $\mathrm{GmbH}$. Funding for KM was provided by the Dutch Ministry of Health, Welfare and Sport. Funding for LK was provided by the Bavarian State Ministry of Finance, Regional Development and Regional Identity via the Bavarian State Ministry of Public Health and Care Services in the context of the Bavarian Coordination Centre for Gambling Issues and the Swedish program grant "Responding to and Reducing Gambling Problems - Studies in Help-seeking, Measurement, Comorbidity and Policy Impacts" financed by the Swedish Research Council for Health, Working Life and Welfare (Forte), grant number 2016-07091.

Authors' contribution: JS proposed the concept and design of the study. Interpretation of data was done by JS, JA, LK, KM, AP and AU. All statistical analyses were done by JA and JS in consultation with $\mathrm{LK}, \mathrm{KM}$ and $\mathrm{AU}$.

Conflict of interest: The authors report no financial or other relationship relevant to the subject of this article.

\section{REFERENCES}

Billieux, J., Schimmenti, A., Khazaal, Y., Maurage, P., \& Heeren, A. (2015). Are we overpathologizing everyday life? A tenable blueprint for behavioral addiction research. Journal of Behavioral Addictions, 4(3), 119-123. https://doi.org/10.1556/2006.4.2015.009.

Bischof, G., Bischof, A., Besser, B., Rumpf, H.-J. (2016). Problematische und pathologische Internetnutzung: Entwicklung eines Kurzscreenings (PIEK). Lübeck: Bundesministerium für Gesundheit.

Blum, K., Sheridan, P. J., Wood, R. C., Braverman, E. R., Chen, T. J. H., Cull, J. G., et al. (1996). The D2 dopamine receptor gene as a determinant of reward deficiency syndrome. Journal of the Royal Society of Medicine 89(7), 396-400. https://doi.org/10. 1177/014107689608900711.

ESPAD Group. (2016a). ESPAD report 2015. Results from the European school survey Project on alcohol and other Drugs. Luxembourg: Publications Office of the European Union.

ESPAD Group. (2016b). ESPAD 2015 methodology. Luxembourg: Publications Office of the European Union.

Field, A. (2013). Discovering statistics using IBM SPSS statistics (4th ed.). Sage Publications.

Griffiths, M. (2005). A 'components' model of addiction within a biopsychosocial framework. Journal of Substance Use, 10(4), 191-197. https://doi.org/10.1080/14659890500114359.

Griffiths, M. D., Király, O., Pontes, H. M., \& Demetrovics, Z. (2015). An overview of problematic gaming. In V. Starcevic, \& E. Aboujaoude (Eds.), Mental health in the digital age: Grave dangers, great promise (pp. 27-45). Oxford: Oxford University Press. 
HBSC. (2016). Growing up unequal: Gender and socioeconomic differences in young people's health and well-being. Health behaviour in school-aged children (HBSC) study: International report from the 2013/2014 survey. Copenhagen: WHO.

Holstein, B. E., Pedersen, T. P., Bendtsen, P., Madsen, K. R., Meilstrup, C. R., Nielsen, L., et al. (2014). Perceived problems with computer gaming and internet use among adolescents: Measurement tool for non-clinical survey studies. BMC Public Health, 14(1), 361. https://doi.org/10.1186/1471-2458-14-361.

Hox, J. J. (2010). Multilevel analysis. Techniques and applications (2nd ed.). New York: Routledge.

Jessor, R. (1987). Problem-behavior theory, psychosocial development, and adolescent problem drinking. British Journal of Addiction, 82(4), 331-342. https://doi.org/10.1111/j.1360-0443. 1987.tb01490.x.

Jia, R., \& Jia, H. H. (2009). Factorial validity of problematic Internet use scales. Computers in Human Behavior, 25(6), 1335-1342. https://doi.org/10.1016/j.chb.2009.06.004.

Kerr, W. C., Greenfield, T. K., \& Midanik, L. T. (2006). How many drinks does it take you to feel drunk? Trends and predictors for subjective drunkenness. Addiction, 101(10), 1428-1437. https:// doi.org/10.1111/j.1360-0443.2006.01533.x.

King, D. L., Haagsma, M. C., Delfabbro, P. H., Gradisar, M., \& Griffiths, M. D. (2013). Toward a consensus definition of pathological video-gaming: A systematic review of psychometric assessment tools. Clinical Psychology Review, 33(3), 331342. https://doi.org/10.1016/j.cpr.2013.01.002.

Kotyuk, E., Magi, A., Eisinger, A., Király, O., Vereczkei, A., Barta, C., et al. (2020). Co-occurrences of substance use and other potentially addictive behaviors: Epidemiological results from the Psychological and Genetic Factors of the Addictive Behaviors (PGA) Study. Journal of Behavioral Addictions, 9(2), 272-288. https://doi.org/10.1556/2006.2020.00033.

Kraus, L., Room, R., Livingston, M., Pennay, A., Holmes, J., \& Törrönen, J. (2020). Long waves of consumption or a unique social generation? Exploring recent declines in youth drinking. Addiction Research \& Theory, 28 (3), 183-193. https://doi.org/ 10.1080/16066359.2019.1629426.

Kraus, L., Seitz, N.-N., Piontek, D., Molinaro, S., Siciliano, V., Guttormsson, U., et al. (2018). Are the times a-changin'? Trends in adolescent substance use in Europe. Addiction, 113 (7), 1317-1332. https://doi.org/10.1111/add.14201.

Kuss, D. J. (2013). Internet gaming addiction: Current perspectives. Psychology Research and Behavior Management, 6, 125. https:// doi.org/10.2147/PRBM.S39476.

Marmet, S., Notari L., \& Gmel, G. (2015). Suchtmonitoring Schweiz - themenheft Internetnutzung und problematische Internetnutzung in der Schweiz im Jahr 2015, Sucht Schweiz, Lausanne, Schweiz.

Marmet, S., Studer, J., Wicki, M., Bertholet, N., Khazaal, Y., \& Gmel, G. (2019). Unique versus shared associations between self-reported behavioral addictions and substance use disorders and mental health problems: A commonality analysis in a large sample of young Swiss men. Journal of Behavioral Addictions, 8(4), 664-677.

Merlo J., Chaix B., Ohlsson H., Beckman A., Johnell K., Hjerpe P., et al. (2006). A brief conceptual tutorial of multilevel analysis in social epidemiology: Using measures of clustering in multilevel logistic regression to investigate contextual phenomena. Journal of Epidemiology \& Community Health, 60(4), 290-297. https:// doi.org/10.1136/jech.2004.029454.

Moffitt, T. E. (1993). Adolescence-limited and life-course-persistent antisocial behavior: A developmental taxonomy. Psychological Review, 100(4), 674.

Nagygyörgy K., Urbán R., Farkas J., Griffiths MD., Zilahy D., Kökönyei G., et al. (2013). Typology and sociodemographic characteristics of massively multiplayer online game players. International Journal of Human-computer Interaction, 29(3), 192-200. https://doi.org/10.1080/10447318.2012.702636.

Pennay, A., Holmes, J., Törrönen, J., Livingston, M., Kraus, L. \& Room, R. (2018). Researching the decline in adolescent drinking: The need for a global and generational approach: Researching the decline in adolescent drinking. Alcohol and Drug Review, 37, S115-S119. https://doi.org/10.1111/dar.12664.

Petry, N. M., \& O'brien, C. P. (2013). Internet gaming disorder and the DSM-5. Addiction, 108(7), 1186-1187. https://doi.org/10. 1111/add.12162.

Raudenbush, S. W., \& Bryk A. S. (2002). Hierarchical linear models. Applications and data analysis methods. Vol. 2., Thousand Oaks, CA: Sage Publications.

Romo, L., Ladner, J., Kotbagi, G., Morvan, Y., Saleh, D., Tavolacci, M. P., et al. (2018): Attention-deficit hyperactivity disorder and addictions (substance and behavioral): Prevalence and characteristics in a multicenter study in France. Journal of Behavioral Addictions, 7(3), 743-751. https://doi.org/10.1556/2006.7.2018.58.

Room, R., Greenfield, T. K., Holmes, J., Kraus, L., Livingston, M., Pennay, A., et al. (2019). Supranational changes in drinking patterns: Factors in explanatory models of substantial and parallel social change. Addiction Research \& Theory, https://doi. org/10.1080/16066359.2019.1689963.

Rumpf, H.-J., Achab, S., Billieux, J., Bowden-Jones, H., Carragher, N., Demetrovics, Z., et al. (2018). Including gaming disorder in the ICD-11: The need to do so from a clinical and public health perspective: Commentary on: A weak scientific basis for gaming disorder: Let us err on the side of caution (van Rooij et al., 2018). Journal of Behavioral Addictions, 1-6. https://doi.org/10. 1556/2006.7.2018.59.

Škařupová, K., Blinka, L., \& Tápal, A. (2018): Gaming under the influence: An exploratory study. Journal of Behavioral Addictions, 7/2, 493-498. https://doi.org/10.1556/2006.7.2018.27.

Sommet, N. \& Morselli, D. (2017). Keep calm and learn multilevel logistic modeling: A simplified three-step procedure using Stata, $\mathrm{R}$, Mplus, and SPSS. International Review of Social Psychology, 30, 203-218.

Thomsen, K. R., Callesen, M. B., Heesse, M, Kvamme, T. L., Pedersen, M. M., Pedersen, M. U., et al. (2018): Impulsivity traits and addiction-related behaviors in youth. Journal of behavioral addictions, 7(2), 317-330. https://doi.org/10.1556/2006.7.2018.22.

Van Rooij, A. J, Ferguson, C. J, Colder Carras, M., KardefeltWinther, D., Shi, J., Aarseth, E., et al. (2018). A weak scientific basis for gaming disorder: Let us err on the side of caution. Journal of Behavioral Addictions, 7(1), 1-9. https://doi.org/10. 1556/2006.7.2018.19.

Van Rooij, A. J., Kuss, D. J., Griffiths, M. D., Shorter, G. W., Schoenmakers, T. M., \& Van De Mheen, D. (2014). The (co-) occurrence of problematic video gaming, substance use, and 
psychosocial problems in adolescents. Journal of Behavioral Addictions, 3(3), 157-165. https://doi.org/10.1556/JBA.3. 2014.013.

Vrieze S. I. (2012). Model selection and psychological theory: A discussion of the differences between the Akaike information criterion (AIC) and the Bayesian information criterion
(BIC) psychol. Methods, 17(2), 228. https://doi.org/10.1037/ a0027127.

World Bank. (2018). GDP per capita. World Bank national accounts data, and OECD National Accounts data files. https://databank. worldbank.org/source/world-development-indicators. Data retrieved on 14 November 2018.

\section{APPENDIX: ADDITIONAL TABLES}

Table 6. Number of students per country and sex

\begin{tabular}{|c|c|c|c|}
\hline Country & Male & Female & Total \\
\hline Albania & 1,216 & 1,337 & 2,553 \\
\hline Austria & 1,901 & 1,793 & 3,694 \\
\hline Bulgaria & 1,453 & 1,469 & 2,922 \\
\hline Croatia & 1,337 & 1,221 & 2,558 \\
\hline Cyprus & 1,008 & 1,090 & 2,098 \\
\hline Czech Republic & 1,361 & 1,412 & 2,773 \\
\hline Denmark & 796 & 874 & 1,670 \\
\hline Estonia & 1,224 & 1,228 & 2,452 \\
\hline Faroe Islands & 257 & 254 & 511 \\
\hline Finland & 1,958 & 2,091 & 4,049 \\
\hline France & 1,363 & 1,351 & 2,714 \\
\hline FYR of Macedonia & 1,179 & 1,249 & 2,428 \\
\hline Georgia & 1,047 & 919 & 1,966 \\
\hline Germany (Bavaria) & 428 & 434 & 862 \\
\hline Greece & 1,583 & 1,619 & 3,202 \\
\hline Hungary & 1,333 & 1,314 & 2,647 \\
\hline Iceland & 1,312 & 1,351 & 2,663 \\
\hline Ireland & 749 & 721 & 1,470 \\
\hline Italy & 2,093 & 1,966 & 4,059 \\
\hline Latvia & 565 & 554 & 1,119 \\
\hline Liechtenstein & 143 & 173 & 316 \\
\hline Lithuania & 1,303 & 1,270 & 2,573 \\
\hline Malta & 1,665 & 1,661 & 3,326 \\
\hline Moldova, Republic of & 1,325 & 1,261 & 2,586 \\
\hline Montenegro & 1,957 & 1,887 & 3,844 \\
\hline Netherlands & 832 & 852 & 1,684 \\
\hline Norway & 1,380 & 1,195 & 2,575 \\
\hline Poland & 1,585 & 1,704 & 3,289 \\
\hline Portugal & 1,568 & 1,888 & 3,456 \\
\hline Romania & 1,711 & 1,789 & 3,500 \\
\hline Slovak Republic & 1,108 & 1,100 & 2,208 \\
\hline Slovenia & 1,675 & 1,809 & 3,484 \\
\hline Sweden & 1,263 & 1,288 & 2,551 \\
\hline Ukraine & 1,170 & 1,302 & 2,472 \\
\hline Total & 42,848 & 43,426 & 86,274 \\
\hline
\end{tabular}

Notes: PPS = perceived problems scale; AGT = average gaming time; PGI = problem gaming indicator; a = cannot be calculated since only boys score positively on the PGI.

Source: 2015 ESPAD survey 
Table 7. Scores of gaming indicators PPS, AGT and PGI by country (using $2 \mathrm{~h}$ per day as the threshold for the AGT and the PGI)

\begin{tabular}{|c|c|c|c|c|c|c|}
\hline & \multicolumn{2}{|c|}{ PPS (2-3 pts) } & \multicolumn{2}{|c|}{ AGT (2h or more) } & \multicolumn{2}{|c|}{ PGI } \\
\hline & $\begin{array}{c}\text { Total prevalence } \\
\text { (\%) }\end{array}$ & $\begin{array}{l}\text { Gender ratio } \\
\text { (m:f) }\end{array}$ & $\begin{array}{c}\text { Total prevalence } \\
\text { (\%) }\end{array}$ & $\begin{array}{c}\text { Gender ratio } \\
\text { (m:f) }\end{array}$ & $\begin{array}{c}\text { Total prevalence } \\
\text { (\%) }\end{array}$ & $\begin{array}{c}\text { Gender ratio } \\
(\mathrm{m}: \mathrm{f})\end{array}$ \\
\hline Albania & 27.6 & 2.1 & 8.3 & 2.9 & 5.4 & 3.1 \\
\hline Austria & 14.8 & 5.8 & 15.9 & 12.6 & 7.3 & 30.7 \\
\hline Bulgaria & 29.8 & 2.2 & 17.7 & 5.5 & 8.6 & 5.8 \\
\hline Croatia & 21.8 & 3.1 & 15.5 & 7.5 & 7.9 & 7.8 \\
\hline Cyprus & 23.8 & 2.2 & 16.0 & 6.6 & 7.7 & 6.2 \\
\hline Czech Republic & 16.8 & 5.8 & 18.7 & 8.6 & 8.5 & 10.5 \\
\hline Denmark & 14.2 & 5.6 & 32.3 & 2.6 & 8.7 & 7.8 \\
\hline Estonia & 17.4 & 4.9 & 24.0 & 10.8 & 10.4 & 14.1 \\
\hline Faroe Islands & 26.4 & 4.6 & 19.0 & 23.6 & 11.2 & 56.1 \\
\hline Finland & 14.1 & 5.3 & 18.1 & 16.4 & 7.0 & 24.2 \\
\hline France & 17.8 & 4.1 & 15.8 & 8.9 & 7.5 & 11.6 \\
\hline FYR of Macedonia & 29.3 & 1.8 & 9.6 & 7.5 & 5.4 & 7.5 \\
\hline $\begin{array}{l}\text { Germany } \\
\text { (Bavaria) }\end{array}$ & 12.9 & 7.0 & 17.0 & 7.7 & 7.5 & 8.4 \\
\hline Georgia & 23.9 & 3.6 & 9.3 & 19.2 & 6.4 & 21.2 \\
\hline Greece & 17.1 & 4.1 & 9.7 & 19.0 & 5.4 & 21.0 \\
\hline Hungary & 17.6 & 4.6 & 14.7 & 5.5 & 7.1 & 7.1 \\
\hline Iceland & 12.9 & 4.8 & 15.3 & 18.0 & 5.2 & 27.6 \\
\hline Ireland & 16.2 & 5.7 & 11.8 & 11.0 & 5.3 & 11.7 \\
\hline Italy & 22.9 & 2.4 & 12.2 & 3.4 & 5.7 & 5.1 \\
\hline Latvia & 31.8 & 1.7 & 20.9 & 6.4 & 10.0 & 14.2 \\
\hline Liechtenstein & 12.7 & 6.9 & 15.6 & 28.5 & 3.5 & $\mathrm{a}$ \\
\hline Lithuania & 25.1 & 2.7 & 22.8 & 4.7 & 9.2 & 8.0 \\
\hline Malta & 23.7 & 3.4 & 16.5 & 7.0 & 9.4 & 11.0 \\
\hline $\begin{array}{l}\text { Moldova, } \\
\text { Republic of }\end{array}$ & 28.9 & 1.8 & 10.0 & 10.3 & 4.7 & 12.0 \\
\hline Montenegro & 26.2 & 2.7 & 10.8 & 7.1 & 6.2 & 6.5 \\
\hline Netherlands & 16.0 & 4.0 & 22.1 & 8.5 & 8.8 & 10.6 \\
\hline Norway & 14.3 & 4.8 & 21.6 & 13.4 & 7.3 & 14.0 \\
\hline Poland & 15.4 & 4.1 & 16.6 & 8.3 & 7.0 & 9.2 \\
\hline Romania & 26.7 & 2.1 & 14.5 & 7.5 & 6.7 & 9.1 \\
\hline Slovak Republic & 21.2 & 3.8 & 16.1 & 3.9 & 7.2 & 7.7 \\
\hline Slovenia & 18.8 & 4.7 & 11.4 & 9.7 & 6.0 & 10.3 \\
\hline Sweden & 20.3 & 3.3 & 26.6 & 15.8 & 10.8 & 17.5 \\
\hline Ukraine & 16.9 & 2.1 & 10.9 & 7.7 & 3.5 & 4.2 \\
\hline Total & 20.3 & 3.1 & 15.4 & 7.6 & 6.7 & 9.8 \\
\hline
\end{tabular}

Notes: PPS = perceived problems scale; AGT = average gaming time; PGI = problem gaming indicator; a = cannot be calculated since only boys score positively on the PGI;

Source: 2015 ESPAD survey. 
Table 8. Bivariate association between the PGI (using $2 \mathrm{~h}$ per day as the threshold) and substance use indicators (male students only)

\begin{tabular}{|c|c|c|c|}
\hline & $\begin{array}{l}\text { ORs of scoring positively on the PGI } \\
\text { and alcohol use in the last } 30 \text { days }\end{array}$ & $\begin{array}{l}\text { ORs of scoring positively on the } \\
\text { PGI and smoking cigarettes in the } \\
\text { last } 30 \text { days }\end{array}$ & $\begin{array}{l}\text { ORs of scoring positively on the } \\
\text { PGI and lifetime cannabis use }\end{array}$ \\
\hline Albania & 2.2 & 1.6 & 1.3 \\
\hline Austria & 0.6 & 0.7 & 0.6 \\
\hline Bulgaria & 0.9 & 1.3 & 0.9 \\
\hline Croatia & 1.1 & 0.9 & 1.0 \\
\hline Cyprus & 1.3 & 1.0 & 0.8 \\
\hline Czech Republic & 0.8 & 1.1 & 1.0 \\
\hline Denmark & 0.7 & 0.3 & 0.3 \\
\hline Estonia & 0.9 & 0.9 & 0.8 \\
\hline Faroe Islands & 0.8 & 1.8 & 1.7 \\
\hline Finland & 0.7 & 0.7 & 0.6 \\
\hline France & 0.7 & 0.8 & 0.6 \\
\hline FYR Macedonia & 1.9 & 1.3 & 1.0 \\
\hline Germany (Bavaria) & 0.7 & 0.6 & 0.6 \\
\hline Georgia & 2.4 & 0.9 & 0.6 \\
\hline Greece & 0.8 & 0.9 & 0.9 \\
\hline Hungary & 0.9 & 0.8 & 0.6 \\
\hline Iceland & 0.7 & 0.8 & 0.5 \\
\hline Ireland & 0.6 & 0.8 & 0.7 \\
\hline Italy & 1.1 & 0.9 & 1.0 \\
\hline Latvia & 0.3 & 0.4 & 0.2 \\
\hline Liechtenstein & 0.2 & 0.5 & 1.0 \\
\hline Lithuania & 1.3 & 0.8 & 0.9 \\
\hline Malta & 0.8 & 0.8 & 0.8 \\
\hline Moldova, Republic of & 1.0 & 0.9 & 1.2 \\
\hline Montenegro & 1.3 & 0.9 & 1.2 \\
\hline Netherlands & 0.8 & 0.9 & 0.8 \\
\hline Norway & 0.9 & 1.1 & 1.2 \\
\hline Poland & 1.1 & 0.9 & 0.7 \\
\hline Romania & 1.0 & 1.3 & 1.0 \\
\hline Slovak Republic & 1.1 & 1.2 & 0.5 \\
\hline Slovenia & 1.0 & 1.3 & 1.1 \\
\hline Sweden & 0.8 & 0.6 & 0.7 \\
\hline Ukraine & 1.0 & 1.3 & 0.9 \\
\hline Total & 0.9 & 0.9 & 0.8 \\
\hline
\end{tabular}

Source: 2015 ESPAD survey. 